14.1

\title{
Биологически активные гибридные наносистемы на основе наночастиц нульвалентного селена и биосовместимых полимеров и ПЭК
}

\author{
(C) С.В. Валуева, ${ }^{1}$ М.Э. Вылегжанина, ${ }^{1}$ П.Е. Алексеева, ${ }^{1,2}$ Т.Е. Суханова ${ }^{1,3}$ \\ ${ }^{1}$ Институт высокомолекулярных соединений РАН, \\ 199004 Санкт-Петербург, Россия \\ ${ }^{2}$ Санкт-Петербургский политехнический университет Петра Великого, \\ 195251 Санкт-Петербург, Россия \\ ${ }^{3}$ Научно-исследовательский институт синтетического каучука им. акад. С.В. Лебедева, \\ 198035 Санкт-Петербург, Россия \\ e-mail: svalu67@mail.ru
}

(Поступило в Редакцию 6 декабря 2017 г.)

\begin{abstract}
Методами статического и динамического светорассеяний, ультрафиолетовой спектроскопии, двойного лучепреломления в потоке, атомно-силовой микроскопии и просвечивающей электронной микроскопии при массовом соотношении $\mathrm{Se}^{0}:$ полимер $v=0.1$ определены молекулярно-конформационные, морфологические и кинетические характеристики селенсодержащих наносистем (НС) на основе модифицированных наночастицами $\mathrm{Se}^{0}$ биосовместимых полимерных матриц различной природы. Определены константы скорости формирования селенсодержащих НС, размерные характеристики соответствующих наноструктур, их форма, молекулярная масса и плотность. Установлено, что в водном растворе образуются изолированные плотные сферические полимолекулярные селенсодержащие наноструктуры. Полученные результаты составляют физико-химическую основу для модификации полимерных материалов с выраженной физиологической активностью биогенными элементами в нульвалентной форме.
\end{abstract}

DOI: $10.21883 / J T F .2018 .09 .46411 .2585$

\section{Введение}

Известно, что биогенный элемент - селен, входящий в состав пищевых продуктов, оказывает антибластическое действие, а между содержанием селена во внешней среде и частотой поражения населения злокачественными опухолями существует обратно пропорциональная зависимость [1]. Известно также, что в условиях дефицита селена наблюдается развитие миокардиодистрофии, атеросклероза, ишемической болезни сердца, инфаркта миокарда и хронического гепатита различной этимологии $[2,3]$.

Ввиду того что гибридные наносистемы обладают синергизмом свойств исходных компонентов, в настоящей работе была проведена модификация наночастицами нуль-валентного селена $\left(\mathrm{Se}^{0}\right)$ биосовместимых полимерных материалов, используемых для получения лекарственных препаратов и БАД [4-6]. Известно, что нуль-валентный селен обладает комплексом уникальных биомедицинских свойств, одним из которых является высокая противоопухолевая активность. Учитывая тот факт, что, например, полиэлектролитный комплекс (ПЭК) обладает мембранотропными свойствами и резко увеличивает проницаемость липидных бислоев [7], он может повысить уровень активности селена. В связи с этим целесообразна модификация наночастицами $\mathrm{Se}^{0}$ биосовместимых полимерных материалов.

Цель настоящей работы - определение методами статического и динамического светорассеяний, УФ спектроскопии, двойного лучепреломления в потоке (ДЛП), атомно-силовой микроскопии (АСМ) и просвечивающей электронной микроскопии (ПЭМ), при массовом соотношении $\mathrm{Se}^{0}$ : полимер $v=0.1$, кинетических, молекулярно-конформационных и морфологических характеристик селенсодержащих наносистем (HC) на основе модифицированных наночастицами $\mathrm{Se}^{0}$ биосовместимых полимерных матриц трех разных типов - синтетического полиамфолита - сополимера акриловой кислоты и $\mathrm{N}, \mathrm{N}$-диметиламиноэтилметакрилата (П(АК-ДМАЭМ $))$, АК : ДМАЭМ = $1: 1$, биополиамфолита - бычьего сывороточного альбумина (БСА) и ПЭК додецилсульфата натрия (ДСН) с катионным сополимером N-винилпирролидона (ВП) и N,N,N,N-триэтилметакрилоилоксиэтиламмоний иодида (К) при $\gamma=Д \mathrm{CH} / \mathrm{K}=0.5$, где $\gamma-$ мольное соотношение заряженных субъединиц. Значения молекулярных масс $\left(M_{w}\right)$ биосовместимых полимерных матриц представлены в таблице.

\section{Экспериментальная часть}

Измерения оптической плотности проводились на спектрофотометре „Specord M40“ (Карл Цейс Йена, Германия) в диапазоне длин волн от 185 до $900 \mathrm{~nm} \mathrm{в}$ термостатируемом режиме, с толщиной фотометрического слоя $1 \mathrm{~cm}$. Расчет величин констант скорости $k^{*}$ процесса самоорганизации селенсодержащих НС был 
проведен по формуле [8] $k^{*}=\ln \left(D_{k} /\left(D_{k}-D_{i}\right)\right) / t_{i}$, где $D_{k}$ - оптическая плотность, характеризующая конец процесса (в нашем случае $24 \mathrm{~h}), D_{i}-$ оптическая плотность в данный момент времени $t_{i}$.

Для измерения $\mathrm{pH}-$ среды использовался милливольтметр И-160МИ.

Методом статического светорассеяния (ССР) [9] определяли средневесовые молекулярные массы $M_{w}^{*}$, среднеквадратичные радиусы инерции $R_{g}^{*}$ селенсодержащих наноструктур, а по величинам второго вириального коэффицента $A_{2}^{*}$ - их сродство к растворителю. По соотношению величин молекулярной массы полимерного стабилизатора (ПС) и образуемой им НС вычисляли количество $N^{*}$ адсорбированных макромолекул на поверхности наночастиц $\mathrm{Se}^{0}$. Значения $M_{w}^{*}, N^{*}, R_{g}^{*}$ и $A_{2}^{*}$ представлены в таблице.

Статическое светорассеяние измеряли на фотогониодиффузометре „Fіса“ при длине волны падающего вертикально поляризованного света $\lambda=546.1 \mathrm{~nm}$. Очистку растворов проводили через миллипору (Millex-HV) диаметром $0.45 \mu \mathrm{m}$. Для калибровки прибора использовали коэффициент рассеяния бензола в вертикально поляризованном свете $R_{90}^{\circ}=22.3 \cdot 10^{6} \mathrm{~m}^{-1}$. Инкременты показателей преломления определяли измерением показателей преломления растворов $(n)$ и растворителя (вода) $\left(n_{s}\right)$ на рефрактометре марки ИРФ-23 при нескольких концентрациях, затем проводили линейную экстраполяцию $\Delta n(c)=n-n_{s}$ по методу наименьших квадратов. Угол наклона $\Delta n(c)$ определял инкремент показателя преломления $d n / d c$.

Обработку результатов измерений светорассеяния для определения $M_{w}^{*}, R_{g}^{*}$ и $A_{2}^{*}$ проводили по методу Дебая с использованием уравнения [9]:

$$
c K / R_{90}^{\circ}=1 / M_{w}^{*} P(\theta)+2 A_{2}^{*} c,
$$

где $c-$ концентрация раствора, $K=4\left(\pi n_{s} d n / d c\right)^{2} /$ $N_{A} \lambda^{4}$ - оптическая постоянная раствора $\left(N_{A}-\right.$ число Авогадро), $R_{90}^{\circ}-$ отношение Рэлея, измеряемое под углом рассеяния $\theta=90^{\circ}, P(\theta)$ - функция рассеяния, определяемая по асимметрии рассеяния $[z]=\lim \left(R_{45}^{\circ} / R_{135}^{\circ}\right)$ при $c \rightarrow 0\left(R_{45}^{\circ}\right.$ и $R_{135}^{\circ}-$ отношение Рэлея при углах рассеяния 45 и $\left.135^{\circ}\right)$. Для определения величины $P\left(90^{\circ}\right)$, отвечающей найденному значению $[z]$, использовали расчетные значения, полученные для сферических частиц [9]. Из этих же данных по значениям [z] находили $D^{*} / \lambda$, где $D^{*}$ - диаметр частицы.

На основании данных по $M_{w}^{*}$ и среднеквадратичным радиусам инерции $R_{g}^{*}$ по формуле

$$
\Phi^{*}=3 M_{w}^{*} / 4 \pi N_{a} R_{s p}^{3}
$$

(здесь $R_{s p}=1.29 R_{g}^{*}$ ) определяли величины средней плотности наноструктур $\Phi^{*}[10]$. Значения $\Phi^{*}$ приведены в таблице.

Гидродинамические радиусы наноструктур $\left(R_{h}^{*}\right)$ определяли методом динамического светорассеяния (ДСР) на корреляционном спектрометре Photo Cor
Complex (источник света - гелий-неоновый лазер фирмы Coherent мощности $20 \mathrm{~mW}$ с длиной волны $\lambda=$ $=632.8 \mathrm{~nm}) \mathrm{c}$ программируемым коррелятором Photocor-FC (число каналов 288, ЗАО „Антекс“, Россия). Обработку корреляционной функции осуществляли с помощью программы Dyna LS („Гелиос“", Россия). Величины гидродинамических радиусов $R_{h}^{*}$ (см. таблицу) рассчитывали из значений коэффицентов диффузии $\left(D^{*}\right)$ по уравнению Эйнштейна-Стокса $R_{h}^{*}=$ $=k T / 6 \pi \eta_{0} D^{*}\left(\eta_{0}-\right.$ вязкость растворителя, $k-$ константа Больцмана, $T-$ температура) [11]. По соотношению экспериментальных величин $R_{g}^{*}$ и $R_{h}^{*}$ находили значение структурно-конформационного параметра $\rho^{*}[12-15]$.

АСМ исследования морфологии селенсодержащих НС проводили на атомно-силовом микроскопе Nanotop NT206 (ОДО „Микротестмашинь“, Беларусь). Измерения выполняли в контактном режиме в атмосферных условиях с использованием кремниевых кантилеверов NSC11/AlBS с коэффициентом жесткости $k=3.0 \mathrm{~N} / \mathrm{m}$ и радиусом кривизны кончика острия $10 \mathrm{~nm}$. Экспериментальные данные обрабатывали с помощью программы SurfaceExplorer.

Исследования методом ПЭМ проводили на электронном микроскопе BS-500 (фирмы Tesla, Чехия) при ускоряющем напряжении $U=60 \mathrm{kV}$, в диапазоне увеличений 9000-30000. Перед исследованием раствор полимера или наносистемы наносили на медную сетку, покрытую формваровой пленкой, и сушили на воздухе.

Методом ДЛП [16] по характеру градиентной зависимости величины ДЛП $\Delta n$ оценивали молекулярную дисперсность растворов образующихся наноструктур. При этом величину ДЛП $\Delta n$ определяли в зависимости от градиента скорости вращения ротора $g$ и концентрации $c$ ПС при фиксированной концентрации селена. Использовали титановый динамооптиметр с внутренним ротором высотой $4 \mathrm{~cm}$ и величиной зазора между ротором и статором $0.03 \mathrm{~cm}$. Все исследования ДЛП проводили при термостатировании растворов $\left(21^{\circ} \mathrm{C}\right)$ во избежание изменений их вязкости и оптических искажений, вызываемых температурным градиентом. Для градуировки установки применяли фенилэтиловый спирт, который обладает значительным ДЛП $\left(\Delta n / g=17 \cdot 10^{-12}(\Delta n-\right.$ разность двух главных показателей преломления раствора)), а также систему полистирол-бромоформ. Погрешность определения характеристической величины ДЛП $[n]=\lim _{g \rightarrow 0, c \rightarrow 0}\left(\Delta n / g c \eta_{0}\right)$ (где $\eta_{0}-$ вязкость растворителя) не превышала $10 \%$. Измерения проводили при $g<g_{k}$, где $g_{k}-$ градиент скорости, при котором наступает турбулентность потока.

Экспериментальная величина $[n]$ в общем случае $d n / d c \neq 0$ складывается из трех эффектов: $[n]=[n]_{e}+$ $+[n]_{f s}+[n]_{f}$, где $[n]_{e}-$ собственная анизотропия, $[n]_{f s}$ - эффект микроформы, $[n]_{f}$ - эффект макроформы $[16]$. При этом величина $[n]_{f}$ связана с асимметрией 
Молекулярно-конформационные и термодинамические параметры для селенсодержащих НС при $v=0.1$ и $\mathrm{pH}=3.8$

\begin{tabular}{l|c|c|c|c|c|c|c|c}
\hline \multicolumn{1}{c|}{$\mathrm{HC}$} & $M_{w} \cdot 10^{-3}$ & $M_{w}^{*} \cdot 10^{-6}$ & $N^{*}$ & $R_{g}^{*}, \mathrm{~nm}$ & $R_{h}^{*}, \mathrm{~nm}$ & $A_{2}^{*} \cdot 10^{4}, \mathrm{~cm}^{3} \cdot \mathrm{mol} / \mathrm{g}^{2}$ & $\Phi^{*}, \mathrm{~g} / \mathrm{cm}^{3}$ & $R_{\mathrm{ACM}}^{*}, \mathrm{~nm}$ \\
\hline $\mathrm{Se}^{0} / \Pi(\mathrm{АК-ДМАЭМ)}$ & $20 \cdot 10^{3}$ & 60 & 3 & 100 & 100 & 0.4 & 0.01 & 120 \\
$\mathrm{Se}^{0} /$ БСА & 70 & 70 & $10^{3}$ & 50 & 50 & 0.2 & 0.10 & 70 \\
$\mathrm{Se}^{0} / \Pi Э К, \gamma=0.5$ & 117 & 10 & 85 & 40 & 40 & 0.5 & 0.03 & 50
\end{tabular}

формы частицы $p^{*}$ соотношением

$$
\begin{aligned}
{[n]_{f} } & =\left(\left(n_{s}^{2}+2\right) / 3\right)^{2}\left(M_{w}(d n / d c)^{2} f(p)\right) /\left(30 \pi R T n_{s}\right) \\
& =\mathrm{const} \cdot M_{w}(d n / d c)^{2} f\left(p^{*}\right)
\end{aligned}
$$

где $n_{s}$ - показатель преломления растворителя, $T$ абсолютная температура, $R$ - универсальная газовая постоянная, $f\left(p^{*}\right)$ - табулированная функция отношения осей жесткого (непротекаемого для растворителя) эллипсоида, аппроксимирующего частицу [16].

\section{Обсуждение результатов}

Константы скорости $k^{*}$ для наносистем $\mathrm{Se}^{0} /$ ПАК-ДМАЭМ), $\mathrm{Se}^{0} /$ БСА и $\mathrm{Se}^{0} /$ ПЭК при $\gamma=0.5$ в условиях полного насыщения адсорбционной емкости наночастиц селена $(v=0.1)$ [17-20] и при фиксированном значении $\mathrm{pH}=3.8$ составили соответственно $3.3 \cdot 10^{3}, 2.5 \cdot 10^{-3}$ и $0.9 \cdot 10^{-3} \mathrm{~s}^{-1}$. Такое существенное изменение величины константы скорости самоорганизации гибридных НС при неизменных значениях параметров среды $(\mathrm{pH})$ указывает на ощутимое влияние структуры (природы) ПС на величину $k^{*}$. Структурноморфологические особенности ПС, используемых в настоящей работе, хорошо иллюстрируют данные, полученные методом АСМ. На рис. 1 представлены АСМ изображения (на слюде) поверхности пленок, полученных из водных растворов ПС-П(АК-ДМАЭМ), БСА и ПЭК (с соотношением $\gamma=0.5$ ). Поверхность пленки П(АК-ДМАЭМ) (рис. $1, a$ ) имеет мелкозернистую (нанодоменную) морфологию, размер зерна составляет $35-40 \mathrm{~nm}$. Пленка достаточно гладкая - величины среднеарифметической $\left(R_{a}\right)$ и среднеквадратичной $\left(R_{q}\right)$ шероховатостей составляют соответственно 0.5 и $0.6 \mathrm{~nm}$, высота зерен над усредненной поверхностью не превышает $3 \mathrm{~nm}$ (рис. 1,d). Тонкая структура пленки, полученной из водного раствора БСА (рис. 1,b), имеет также зернистую морфологию, размер зерна $\sim 70-90 \mathrm{~nm}$; кроме того, на поверхности наблюдаются отдельные частицы с размерами 100-200 nm, максимальная высота которых над поверхностью не превышает $14 \mathrm{~nm}$ (рис. 1,e). Пленка, отлитая из раствора БСА, более шероховатая, величины шероховатости составляют: $R_{a}=1.6 \mathrm{~nm}$ и $R_{q}=2.3 \mathrm{~nm}$. Совершенно иная морфология наблюдается в случае пленки, полученной из водного раствора ПЭК (рис. $1, c, f)$ : на поверхности наблюдаются крупные агрегаты субмикронных и микронных размеров длиной 750-1500 nm и шириной
450-900 nm; максимальная высота над поверхностью этих агрегатов составляет $\sim 50 \mathrm{~nm}$.

Оценка гидродинамического радиуса $R_{h}^{*}$ наночастиц селена (при $v=0.1$ ) методом ДСР показала, что в отсутствие ПС образуются крупные частицы с радиусом $\sim 180 \mathrm{~nm}$, с узким унимодальным распределением по размерам. По истечении двух суток происходит визуально видимая агрегация наночастиц селена, выпадающих в осадок. При использовании в качестве полимерного стабилизатора П(АК-ДМАЭМ), БСА или ПЭК в водных растворах формируются наноструктуры с размером $\leq 100 \mathrm{~nm}$ (см. таблицу), при этом наносистемы характеризуются узким унимодальным распределением по размерам и достаточно высокой стабильностью.

Информацию об изменении молекулярной массы $\left(M_{w}^{*}\right)$, размеров $\left(R_{g}^{*}\right.$ и $\left.R_{h}^{*}\right)$ и формы $\left(\rho^{*}, p^{*}\right)$ наноструктур дают методы ССР, ДСР и ДЛП. Величина молекулярной массы при переходе от водных растворов полимеров или ПЭК к НС в зависимости от природы ПС возрастала в 3 раза (ПС-П(АК-ДМАЭМ)), 85 раз (ПЭК) и 1000 раз (БСА), т.е. на поверхности НЧ адсорбировано $3 \cdot 10^{3}$ молекул полимера $\left(N^{*}=29-61\right)$ (см. таблицу). При этом сохранялось молекулярнодисперсное состояние растворов наноструктур, о чем свидетельствовал характер градиентных зависимостей $\Delta n=f(g)$ : при $g<g_{\kappa}$ (где $g_{\kappa}-$ величина критического градиента скорости, при котором наступает турбулентность потока, а исследования следует проводить только при ламинарном течении жидкости [16]) для всех изученных НС они хорошо аппроксимируются прямыми линиями, проходящими через начало координат [16].

Важно также отметить, что для изученных гибридных НС величина среднеквадратичного радиуса инерции $R_{g}^{*}$ совпадает с величиной гидродинамического радиуса $R_{h}^{*}$ (см. таблицу) и значение структурноконформационного параметра $\rho^{*}=R_{g}^{*} / R_{h}^{*}$ составляло $\rho^{*}=1.0$, что характерно для глобулярных образований - сплошных однородных сфер [12-15]. Эти значения $\rho^{*}$ существенно меньше величины структурноконформационного параметра для клубкообразных макромолекул в термодинамически хорошем растворителе $\left(\rho_{\text {coil }}=1.5-1.7\right)$ [12-15]. Формирование наноструктур с формой, близкой к сферической, экспериментально обнаружено также в работах [4-6,17-21].

Оценка величины параметра $p^{*}$ для исследованных наноструктур в приближении $[n] \sim[n]_{f}$ на основании соотношения (2) показала, что для всех изученных НС характерна сферическая форма наноструктур $\left(p^{*}=1.0-1.2\right)$. 

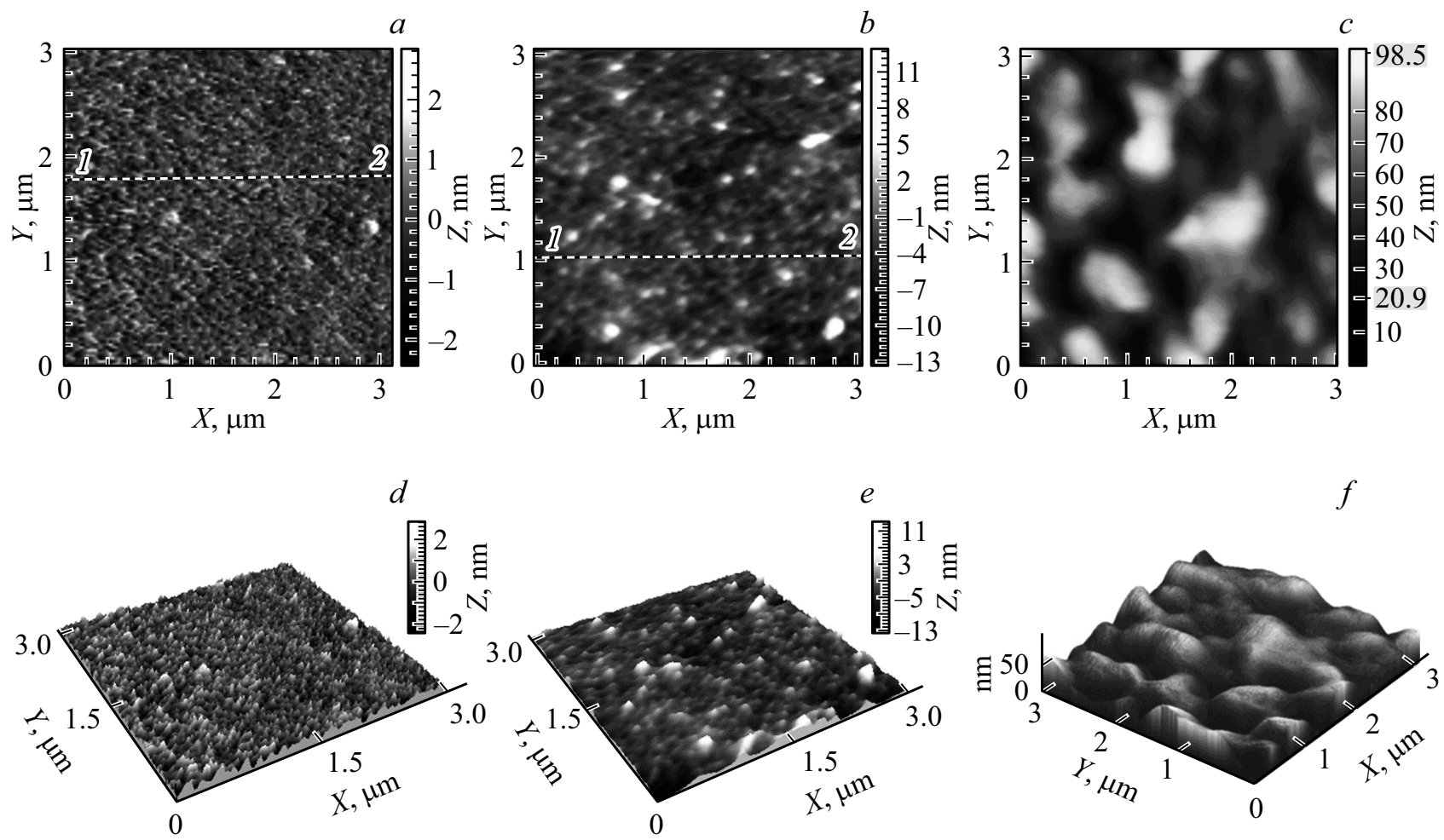

Рис. 1. АСМ изображения: свободного сополимера П(АК-ДМАЭМ) в воде $(a, d)$; БСА в воде $(b, e)$; ПЭК с соотношением $\gamma=0.5$ в воде $(c, f) ; a-c-$ изображения высоты поверхности (топография: размер скана $3 \times 3 \mu \mathrm{m}), d-f-3 \mathrm{D}$-изображения.
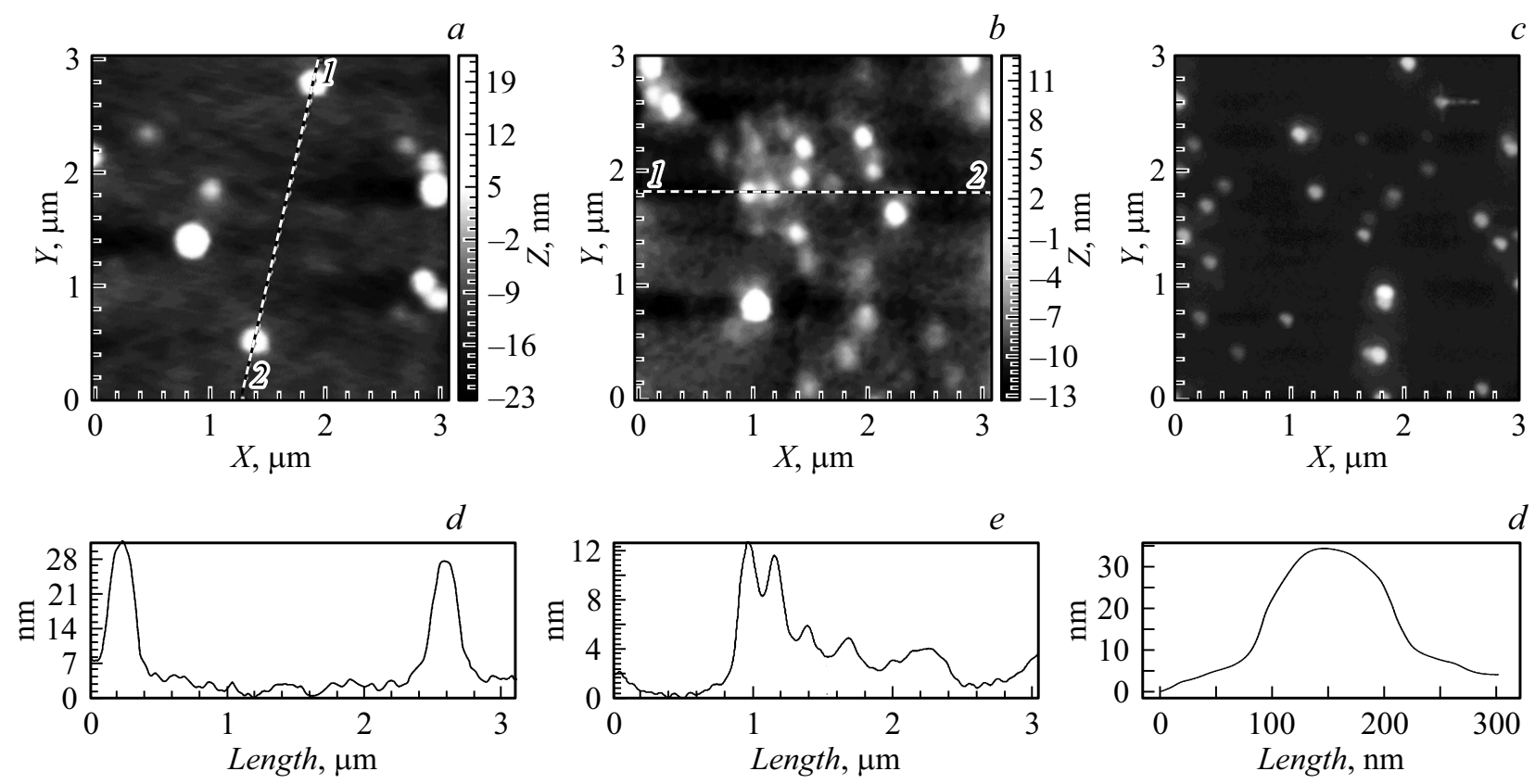

Рис. 2. АСМ изображения поверхности пленки, полученной из водного раствора селенсодержащих НС $(v=0.1)$ : П(АК-ДМАЭМ $) / \mathrm{Se}^{0}(a, d) ;$ БСА/ $/ \mathrm{Se}^{0}(b, e)$ и ПЭК/ $\mathrm{Se}^{0}(c, f) ; a-c-$ изображения высоты поверхности, $d-f-$ профили выделенных участков поверхности.

Это полностью согласуется с данными по параметру $\rho^{*}\left(\rho^{*}=1.0\right)$ и данными $\mathrm{ACM}$ (рис. $\left.2, a-c\right):$ на АCM изображениях поверхности тонких пленок, отлитых из

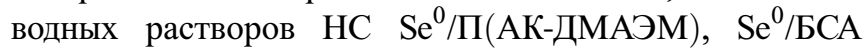

и $\mathrm{Se}^{0} / П Э К$, четко видны сферические наноструктуры. Это также подтверждается результатами, полученными методом ПЭМ для пленки, высушенной из водного

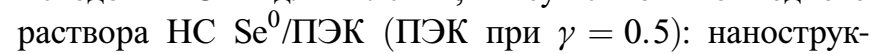




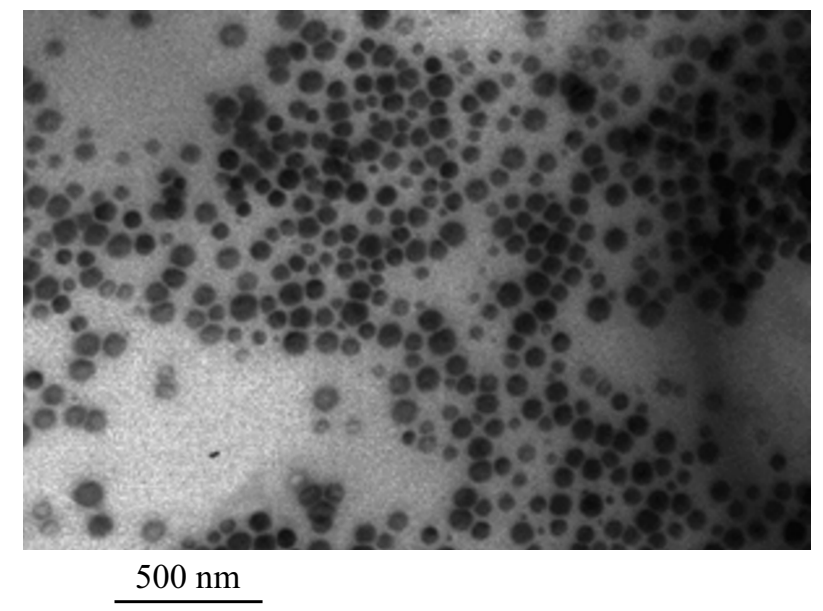

Рис. 3. ПЭМ микрофотография тонкой пленки, приготовленной из раствора НС ПЭК/ $/ \mathrm{Se}^{0}(\gamma=0.5)$.

туры $\mathrm{Se}^{0} /$ моноядерные сферические структуры (рис. 3).

Важно отметить, что прослеживается хорошая корреляция величин размерных характеристик изученных наноструктур, полученных методами $\mathrm{CCP}\left(R_{s p}^{*}=\right.$ $\left.=1.29 \cdot R_{g}^{*}\right)$ и $\mathrm{ACM}\left(R_{\mathrm{ACM}}^{*}\right)$ (см. таблицу и рис. 2$)$. Так, средние величины радиусов сферических наноструктур, полученные методом АСМ для $\mathrm{HC} \mathrm{Se} 0 /$ (АК-ДМАЭМ) составляют $R_{\mathrm{ACM}}^{*}=120 \mathrm{~nm} \quad\left(R_{s p}^{*}=129 \mathrm{~nm}\right)$, для $\mathrm{HC}$ $\mathrm{Se}^{0} /$ БСА $R_{\mathrm{ACM}}^{*}=70 \mathrm{~nm}\left(R_{s p}^{*}=65 \mathrm{~nm}\right)$ и для $\mathrm{HC} \mathrm{Se}^{0} / \Pi Э К$ $R_{\mathrm{ACM}}^{*}=50 \mathrm{~nm}\left(R_{s p}^{*}=52 \mathrm{~nm}\right)$.

Расчет средней плотности НС по формуле (1) показал, что в зависимости от природы ПС формируются НC с плотностью в диапазоне $\Phi^{*}=0.01-0.10 \mathrm{~g} / \mathrm{cm}^{3}$ (см. таблицу), существенно превосходящей плотность полимерного клубка [16]. Важно отметить, что наименее плотные наноструктуры образуются в случае НС $\mathrm{Se}^{0} / \Pi$ (АК-ДМАЭМ), а наиболее плотные наноструктуры наблюдаются при стабилизации наночастиц селена молекулами БСА. Таким образом, более массивная частица (ПС-БСА) оказывается и более плотной: $M_{w}^{*}=70 \cdot 10^{6}$ и $\Phi^{*}=0.10 \mathrm{~g} / \mathrm{cm}^{3}$ (см. таблицу). Очевидно, что изученные наноструктуры имеют различные упаковку и распределение органических молекул вокруг селенового ядра (ядер). Так, сопоставление величины контурной длины белковой макромолекулы $L$ [16] с величиной $R_{s p}^{*}=65 \mathrm{~nm}$ показало, что наноструктура $\mathrm{Se}^{0} /$ БСА является полиядерной: $L \ll R_{s p}^{*}$.

Как известно [22], свободная энергия $\Delta G^{*}$ взаимодействия макромолекула-наночастица в расчете на единицу площади поверхности частицы может быть определена по соотношению

$$
\Delta G^{*}=k T \ln c / 4 \pi R_{s p}^{2},
$$

где $c-$ начальная концентрация полимера в mol/l. Отметим, что соотношение (3) справедливо для сферических наноструктур произвольной морфологии в области образования устойчивых дисперсий. Применение уравнения (3) к исследованным наноструктурам показало, что в случае $\mathrm{HC} \mathrm{Se} /$ (АК-ДМАЭМ) $\Delta G^{*}=$ $=-0.02 \cdot 10^{-5} \mathrm{~J} / \mathrm{m}^{2}$, для $\mathrm{HC} \quad \mathrm{Se}^{0} / Б \mathrm{БCA} \quad \Delta G=$ $=-0.07 \cdot 10^{-5} \mathrm{~J} / \mathrm{m}^{2}$, а для $\mathrm{HC} \mathrm{Se}^{0} /$ ПК с соотношением ДСН/К $\gamma=0.5 \Delta G=-0.06 \cdot 10^{-5} \mathrm{~J} / \mathrm{m}^{2}$. Таким образом, при использовании в качестве ПС сополимера П(АК-ДМАЭМ) свободная энергия $\Delta G^{*}$ взаимодействия макромолекула-наночастица селена заметно меньше по абсолютной величине, чем аналогичная величина для $\mathrm{HC} \mathrm{Se}^{0} /$ БСА и $\mathrm{Se}^{0} / П Э К$.

Итак, изученные сферические наноструктуры ощутимо различаются по значениям молекулярных масс, размерам и плотности, кроме того, при варьировании природы ПС ощутимо изменяются энергия и характер взаимодействий наночастиц $\mathrm{Se}^{0}$ с ПС, что отражает параметр $\Delta G^{*}$.

Второй вириальный коэффициент $A_{2}^{*}$ для изученных НС стремится к нулю $\left(A_{2}^{*}=(0.2-0.5) \cdot 10^{-4} \mathrm{~cm}^{3} \cdot \mathrm{mol} / \mathrm{g}^{2}\right.$ (см. таблицу)), что характеризует состояние растворов как близкое к идеальному (близком к тета-точке). Следует заметить, что для исследованной в настоящей работе $\mathrm{HC} \mathrm{Se}^{0} / \Pi Э К$ при $\gamma=0.5$ наличие в растворе селена практически не сказывается на его термодинамическом состоянии, в то время как при $\gamma=4.0$ [4] переход от системы ПЭК-вода к системе $\mathrm{Se}^{0} / П Э К$-вода сопровождался кардинальным изменением термодинамического состояния раствора от хорошего $\left(A_{2}^{*}=22 \cdot 10^{-4} \mathrm{~cm}^{3} \cdot \mathrm{mol} / \mathrm{g}^{2}\right)$ к плохому $\left(A_{2}^{*}=\right.$ $\left.=-1.8 \cdot 10^{-4} \mathrm{~cm}^{3} \cdot \mathrm{mol} / \mathrm{g}^{2}\right), \quad$ по-видимому, вследствие ориентации гидрофобных алкильных цепей ДСН в объемную фазу раствора (система-Sе $\mathrm{S}^{0} /$ ПЭК-вода).

\section{Заключение}

Методами светорассеяния, УФ спектроскопии, ДЛП, АСМ и ПЭМ показано, что гибридные селенсодержащие наносистемы на основе биосовместимых полимерных матриц трех разных типов - синтетического полиамфолита - сополимера акриловой кислоты и $\mathrm{N}, \mathrm{N}$-диметиламиноэтилметакрилата, биополиамфолита - бычьего сывороточного альбумина и полиэлектролитного комплекса при $\gamma=Д С Н / К=0.5$ различаются по кинетическим $\left(k^{*}\right)$, размерным $\left(R_{h}^{*}, R_{g}^{*}, R_{\mathrm{ACM}}^{*}\right)$, молекулярно-массовым $\left(M_{w}^{*}\right)$, термодинамическим $\left(A_{2}^{*}\right)$ параметрам, плотности $\left(\Phi^{*}\right)$ и величине свободной энергии $\left(\Delta G^{*}\right)$. Таким образом, показано, что структура (природа) стабилизирующего полимера является определяющим фактором в процессе формирования гибридных селенсодержащих наноструктур и оптимизации их параметров (константы скорости, размерных характеристик, формы, молекулярной массы, плотности, термодинамического параметра и величины свободной энергии). Полученные результаты составляют физико-химическую основу для целенаправленного синтеза потенциальных лекарственных веществ на основе селена. 


\section{Список литературы}

[1] Yoshizawa K., Willett W.C., Morris S.J. // J. Natl. Cancer Inst. 1998. Vol. 90. N 16. P. 1219-1224.

DOI: $10.1093 /$ jnci/90.16.1219

[2] Абдуллаев Г.М., Зейналль Э.М., Сафаров Ю.И. // Врачебное дело. 1978. № 11. С. 35-37.

[3] Yu S.Y., Zhu Y.J., Li W.G. // Biol. Trace Element Res. 1997. Vol. 51. N 1. P. 117-124. DOI: $10.1007 / \mathrm{BF} 02778987$

[4] Валуева С.В., Боровикова Л.Н., Волков А.Я. // Сборник статей по материалам Международной научнопрактической конф. „Дни науки“. 2012. Прага, Чехия. C. 24-32.

[5] Валуева С.В., Суханова Т.Е., Матвеева Н.А., Вылегжсанина М.Э., Гельфонд М.Л. // Сборник статей Второй Международной научно-практической конф. „Высокие технологии, фундаментальные и прикладные исследования в физиологии и медицине“ (PhysioMedi). 2011. СанктПетербург, Россия. С. 130-137.

[6] Валуева С.В., Азизбекян С.Г., Кучинский М.П., Набиуллин А.P., Суханова T.E. // Нанотехника. 2012. № 4 (32). C. 53-58.

[7] Копейкин В.В. // Биологич. мембраны. 1988. Т. 5. № 7. C. $728-734$

[8] Березин И.В., Клесов А.А. Практический курс химической и ферментативной кинетики. М.: МГУ, 1976. 320 с.

[9] Эскин B.E. Рассеяние света растворами полимеров и свойства макромолекул. Л.: Наука, 1986. 288 с.

[10] Pogodina N.V., Tsvetkov N.V. // Macromolecules. 1997. Vol. 30. N 17. P. 4897-4904. DOI: $10.1021 / \mathrm{ma} 9617983$

[11] Brown W. Dynamic Light Scattering: the Method and Some Application. Oxford: Clarondon Press, 1993. 305 p.

[12] Meewes M., Ricka J., De Silva M., Nuffengger R., Binkert Th. // Macromolecules. 1991. Vol. 24. N 21. P. 58115816. DOI: $10.1021 / \mathrm{ma} 00021 \mathrm{a} 014$

[13] Nishio I., Shao Thang Sun, Swislow G., Tanaka T. // Nature. 1979. Vol. 281. N 5728. P. 208-209. DOI: $10.1038 / 281208$ a0

[14] Konishi T., Yoshizaki T., Yamakawa H. // Macromolecules. 1991. Vol. 24. N 20. P. 5614-5622.

DOI: $10.1021 / \mathrm{ma} 00020 \mathrm{a} 021$

[15] Burchard B.W. Static and dynamic light scattering approaches to structure determination of biopolymers / Laser Light Scattering in Biochemistry Eds by S.E. Harding, D.B. Satelle, V.A. Bloomfild. Cambridge: Royal Soc. Chem. Information Services, 1992. P. 3-21.

[16] Цветков В.Н., Эскин В.Е., Френкель С.Я. Структура макромолекул в растворах. М.: Наука, 1964. 720 с.

[17] Валуева С.В., Боровикова Л.Н., Коренева В.В., Назаркина Я.И., Киппер А.И., Копейкин В.В. // Журн. физ. химии. 2007. Т. 81. № 7. С.1329-1333.

[18] Валуева С.В., Боровикова Л.Н., Киппер А.И. // Журн. физ. химии. 2008. Т. 82. № 6. С. 1131-1136.

[19] Валуева С.В., Боровикова Л.Н. // Бутлеровские сообщения. 2010. Т. 20. № 5. С. 52-61.

[20] Валуева С.В., Вылегжанина М.Э., Лаврентьев В.К., Боровикова Л.Н., Суханова Т.Е. // Журн. физ. химии. 2013. T. 87. № 3. C. 499-504. DOI: $10.7868 /$ S0044453713030345

[21] Валуева С.В., Титова А.В., Боровикова Л.Н. // Журн. физ. химии. 2015. Т. 89. № 9. С. 1420-1425. DOI: $10.7868 / \mathrm{S} 0044453715090368$

[22] Литманович А.А., Паписов И.М. // Высокомолекулярные соединения. Б. 1997. Т. 39. № 2. С. 323-326. 